\title{
Intraspecific variation in the diet of the Mexican garter snake Thamnophis eques
}

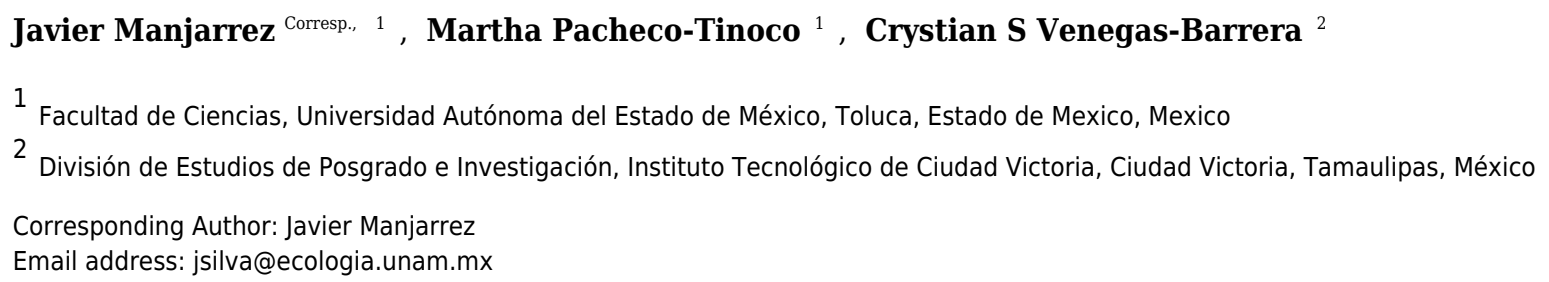

The Mexican Garter Snake (Thamnophis eques) is a terrestrial-aquatic generalist that feeds on both aquatic and terrestrial prey. We describe size-related variation and sexual variation in the diet of $T$. eques through analysis of 262 samples of identifiable stomach contents in snakes from 23 locations on the Mexican Plateau. The snake $T$. eques we studied consumed mostly fish, followed in lesser amounts by leeches, earthworms, frogs, and tadpoles. Correspondence analysis suggested that the frequency of consumption of various prey items differed between the categories of age but not between sex of snakes, and the general pattern was a reduction of prey item diversity with size of snake. Snake length was correlated positively with mass of ingested prey. Large snakes consumed large prey and continued to consume smaller prey. In general, no differences were found between the prey taxa of male and female snakes, although males ate two times more tadpoles than females. Males and females did not differ in the mass of leeches, earthworms, fishes, frogs and tadpoles that they ate, and males and females that ate each prey taxon were similar in length. We discuss proximate and functional determinants of diet and suggest that the observed intraspecific variation in $T$. eques could be explored by temporal variation in prey availability, proportions of snake size classes and possible sexual dimorphism in head traits and prey dimensions to assess the role of intersexual resource competition. 


\section{Intraspecific variation in the diet of the Mexican garter}

\section{2 snake Thamnophis eques}

4 Javier Manjarrez ${ }^{1}$, Martha Pacheco-Tinoco ${ }^{2}$, Crystian S. Venegas-Barrera ${ }^{3}$

$5{ }^{1}$ Facultad de Ciencias, Universidad Autónoma del Estado de México, Toluca, Estado de México,

6 México

$7 \quad 2$ Facultad de Ciencias, Universidad Autónoma del Estado de México, Toluca, Estado de México,

8 México

$9{ }^{3}$ División de Estudios de Posgrado e Investigación, Instituto Tecnológico de Ciudad Victoria,

10 Ciudad Victoria, Tamaulipas, México

12 Corresponding Author:

13 Javier Manjarrez ${ }^{1}$

14 Instituto Literario 100, Toluca, Estado de México, CP 50000, México

15 Email address: jsilva@ecologia.unam.mx

\section{Abstract}

18 The Mexican Garter Snake (Thamnophis eques) is a terrestrial-aquatic generalist that feeds on

19 both aquatic and terrestrial prey. We describe size-related variation and sexual variation in the

20 diet of $T$. eques through analysis of 262 samples of identifiable stomach contents in snakes from

2123 locations on the Mexican Plateau. The snake T. eques we studied consumed mostly fish,

22 followed in lesser amounts by leeches, earthworms, frogs, and tadpoles. Correspondence analysis

23 suggested that the frequency of consumption of various prey items differed between the 
categories of age but not between sex of snakes, and the general pattern was a reduction of prey item diversity with size of snake. Snake length was correlated positively with mass of ingested prey. Large snakes consumed large prey and continued to consume smaller prey. In general, no differences were found between the prey taxa of male and female snakes, although males ate two times more tadpoles than females. Males and females did not differ in the mass of leeches, earthworms, fishes, frogs and tadpoles that they ate, and males and females that ate each prey taxon were similar in length. We discuss proximate and functional determinants of diet and suggest that the observed intraspecific variation in $T$. eques could be explored by temporal variation in prey availability, proportions of snake size classes and possible sexual dimorphism in head traits and prey dimensions to assess the role of intersexual resource competition.

\section{Introduction}

The Mexican Garter Snake (T. eques) is a medium-sized garter snake classified as a generalist predator because it feeds on both aquatic and terrestrial prey; mostly frogs, tadpoles, and fish, supplemented by lizards and mice (Drummond \& Macías Garcia, 1989; Manjarrez, 1998). Drummond \& Macías Garcia (1989) found that T. eques at Tecocomulco, Hidalgo, is locally specialized in feeding on only two to three taxa. This snake forages in vegetative cover along the shore and an attack may include a sudden lunge across the surface toward prey (Drummond \& Macías Garcia, 1989).

Although T. eques is widely distributed over the Mexican Plateau, in this area, the disturbance and loss of habitat have caused the isolation and fragmentation of their populations (Conant, 2003; Manjarrez, Contreras-Garduño, \& Janczur, 2014), with low population densities and constricted distribution (Rossman, Ford, \& Seigel, 1996; Manjarrez, 1998). This scenario raises the possibility of intraspecific dietary differences by spatial variation of the environment. 
47 In general, garter snakes show important ecological intraspecific variation (Rossman, Ford, \&

Seigel, 1996), and reports on diet for T. eques in Mexico showed sexual, ontogenetic (neonatesadults) and seasonal (rainy-dry) divergence in prey size (Macías Garcia \& Drummond, 1988;

Drummond \& Macías Garcia, 1989; Manjarrez, Contreras-Garduño, \& Janczur, 2014). For example, at Lake Tecocomulco, Mexico, small snakes fed mainly on aquatic invertebrates (leeches and earthworms), while large snakes fed on aquatic vertebrates (frogs, fish, and salamander larvae). Fluctuations in prey availability was associated with seasonal variation in prey (Macías Garcia \& Drummond, 1988). At Toluca, Mexico, snakes T. eques were detected to have eaten earthworms, tadpole, slugs and mice (Manjarrez, 1998; Manjarrez, ContrerasGarduño, \& Janczur, 2014).

In this study, we provide the first broad description of the diet of T. eques on the Mexican Plateau. We looked for variation in consumption of prey type, sex and size-classes of snake from three different drainages. To permit more extensive and novel comparisons, we pooled our dietary records with those of Lozoya (1988) and Drummond \& Macías Garcia (1989), as described in Materials and Methods.

Sexual differences in snake diets show that females sometimes ingest larger prey than males (Shine, 1993; Seigel, 1996; Daltry, Wuster, \& Thorpe, 1998) and this difference is usually attributed to sexual dimorphism in body size when females are bigger that males. The maximum size of prey that can be ingested is constrained by a snake's gape (e.g. King, 2002), and in most species, larger snakes take larger prey and appear to drop small prey from their diet, although data from very young snakes is usually limited (review in Arnold, 1993). Garter snakes are sexually dimorphic in body size (Shine, 1993) and their diet can vary with age/size-classes (Mushinsky, 1987; Macías Garcia \& Drummond, 1988; amongst others). Female garter snakes 
70 are usually larger than males (Shine, 1994) but sexual differences in garter snake diets have not

71 been well studied (Seigel, 1996). Thamnophis eques is sexually dimorphic with adult females

72 being 5.6\% larger than males in snout-vent length (SVL; Manjarrez, 1998; Manjarrez, Contreras-

73 Garduño, \& Janczur, 2014).

\section{Materials \& Methods}

This study received the approval of the ethics committee of the Universidad Autónoma del Estado de México (Number 4047/2016SF). All subjects were treated humanely on the basis of guidelines outlined by the American Society of Ichthyologists and Herpetologists (ASIH, 2004). We collected snakes along streams, rivers, canals, ponds, and lakes. We measured each captured snake (SVL in $\mathrm{cm}$ ), and also recorded sex in adults by visual inspection of the tail-base breadth or by manually everting the hemipenis in small snakes (Conant \& Collins, 1998). Although the snakes were weighed, these data were not used in this study. Each snake was forced to regurgitate stomach contents by abdominal palpation (Carpenter, 1952). After processing, snakes were released at their capture sites. We measured the wet mass of each prey item and then fixed them in $10 \%$ formalin and preserved them in $70 \%$ alcohol.

We sampled snake stomach contents at 23 sites on the Mexican Plateau (Lerma, Tula, and Nazas, drainages, Table S1) sporadically during the active reproductive season (February to November) over a period of 16 years (Table S2). The sites in the Lerma and Tula drainages were sampled from 1980-1986 and 1991-1995. We obtained 194 regurgitations from 22 sites in Jalisco, Michoacán, México, Hidalgo, and Queretaro. The records obtained for these two drainages are partially reported by Lozoya (1988, 19\% of the total regurgitations), a reference inaccessible to most readers. 
92

In the Nazas drainage we obtained 68 regurgitations. The Nazas population inhabits an isolated 0.36 ha spring-fed cattle pond in the Chihuahuan Desert with a rainy season from June through October. The records were obtained during 27 2-4 day visits, bimonthly during April to November 1981, and monthly during February through December 1982, and February through November 1983. Drummond \& Macías Garcia (1989) previously reported 13\% of the total these records. Snakes were captured on the first two days of each visit and released on the second day to prevent repeat sampling during the same visit. We counted and classified prey items as fish, leeches, frogs, tadpoles, and earthworms.

\section{Analysis}

We classified snakes as neonates $(<20.5 \mathrm{~cm}$ SVL), juveniles $(20.5-39.5 \mathrm{~cm})$ or adults $(>39.5$ cm; Manjarrez, 1998). Percentages of regurgitations containing each prey taxon were normalized by arcsine transformation (Zar, 1984). We used MANCOVA (with snake length as a covariate) to explore variation in the mass of prey consumed by prey taxa and by the sex of each snake. We included complementary analyses of dietary variation in relation to snake size whenever these could contribute to understanding variation in diet. For analyses of prey mass we excluded taxa represented by fewer than five prey items. Prey mass and snake length were natural log transformed prior to calculating correlations because of the lack of homoscedasticity and skewed distributions.

To avoid making Type I or II errors when many Chi square $\left(X^{2}\right)$ tests are performed, we used a Multiple Correspondence Analysis (MCA) to associate prey items consumed more frequently (earthworm, tadpole, fish, frog and leech, considered as not continuous data) by the combination of two categorical variables, the sex of snake (male-female) and snake size (neonates, juveniles, and adults). The analysis is a modification of $X^{2}$ used to analyze 
115 contingency tables and creates a Cartesian diagram based on the association between more than 116 three categorical variables (Legendre \& Legendre, 2003). The diagram display simultaneously

117 the relative position (canonical position) of studied variables categories (Gotelli, 2001). The

118 nearest canonical positions of different variables represent a high association, while distant

119

120

categories show lower association. The degrees of freedom $(d f)$ and probability $(P)$ for MCA have no statistical relevance, because both were used only in two-way table, therefore, we do not report these values. However, similar to $X^{2}$ test, the MCA estimate the differences between observed and expected values, which allow estimate contribution of each variable to $X^{2}$ test value. The analyses generates a coordinate system of reference that account variations of all variables (dimensions), where we reported the first two dimensions, which represents the higher variations. Finally, the center of graph (coordinate 0,0$)$ was the average of all variables, therefore categories nearest to center of graph show a lower association to rest of categories.

Additionally, we performed a Cluster analysis to identify groups of categories of age and sex of snakes with similar consumption of prey, we used the Morisita index of similarity between frequencies of prey consumed, and the Ward's Method of amalgamation (Rencher, 2002). Ward's Method attempts to minimize the Sum of Squares (SS) of any two hypothetical clusters that can be formed at each step (Legendre \& Legendre, 2003), and it is considered as very efficient method, due reduce cluster long chains produced by other joining amalgamation methods as nearest neighbor or UPGMA. The number of groups retained were determined by graph of amalgamation schedule. The graph shows a line graph of the linkage distances at successive clustering steps, the optimal cut-off to deciding how many clusters to retain is when the linkage distance line forms a plateau. Multiple Correspondence and Cluster Analyses are complementary, the MCA identify associations among categories of different categorical 
138 variables, but cannot determine differences; while cluster create groups of different elements, but

139 we cannot know why they are different.

140 Results

141 Prey items

142 We obtained identifiable stomach contents from 262 (38\%) of 690 T. eques collected. Thirteen 143 regurgitations (5.7\% of total) included more than one prey species, and hence contributed more 144 than one data point for some snakes. In order of percentage of prey items identified we found $14542.4 \%(n=111$ regurgitations) consumed fish, $23.7 \%(n=62)$ leeches, $10.6 \%(n=28)$ 146 earthworms, $10.2 \%(n=27)$ frogs, $9.8 \%(n=25)$ tadpoles, and $2.3 \%(n=6)$ axolotls 147 (Ambystoma sp.). Lizard, slug, and mouse were recovered from only 1 stomach each. 148 Our Multiple Correspondence Analysis $\left(X^{2}=2,410.1\right)$ shows that prey type variable 149 contributes with $71.6 \%$ of $X^{2}$ test value $\left(X^{2}=1,725.9\right)$, while snake size with $19.5 \%\left(X^{2}=468.6\right)$ and sex with $8.9 \%\left(X^{2}=215.6\right)$. Canonical position of adult snakes was closer to tadpoles, frogs,

151

and axolotls, therefore adults tend to feed more frequently these prey types than juveniles and neonates snakes (Fig. 1). Juveniles consumed more earthworms, while neonates principally leeches (Fig. 1). Canonical position of male and female snakes showed a lower variation on the prey type consumed (Fig. 1). Cluster analysis indicated that the three size classes differ in prey type consumed (Fig. 2), where adult snakes were closer to juveniles, and both distant to neonate. Prey types consumed by female and male snakes were similar, due linkage distance nodes of males and females of the same size classes was lower than cutoff value. This grouping of snakes suggests a scheme of ontogenetic change in the taxon of prey, with lower relevance of the grouping by sex (Fig. 2).

\section{Variation with snake length}


161

162

163

Snakes of different sizes ate a changing diversity of prey types. The general pattern was a reduction of number of prey item with increasing snake body size. (Fig. 3). Snakes $<65 \mathrm{~cm} \mathrm{SVL}$ ate all prey types of all sizes, including invertebrates (leeches and earthworms) and vertebrates (tadpoles, fish, and frogs). Vertebrate prey were taken by only the largest snakes ( $>60 \mathrm{~cm} \mathrm{SVL})$. At $15 \mathrm{~cm} \mathrm{SVL}$, snakes eat leeches as one of two major prey items, but at $55 \mathrm{~cm} \mathrm{SVL}$ consumption of leeches decreases drastically and disappears completely in larger snakes $>65 \mathrm{~cm}$ SVL (Fig. 3). The consumption of fish and tadpoles increases when snake body size increases. However, the longer snakes $>75 \mathrm{~cm}$ SVL consume only fish and tadpoles while excluding all other prey, possibly because longer snakes were a very small part of the entire sample $(n=7$ stomach contents).

Snake length was correlated positively with mass of ingested prey $\left(r=0.42, F_{1,326}=\right.$ 71.52, $P<0.001$; Fig. 4). Large snakes consume large prey and continue to consume smaller prey. The same relationship was presented for leeches $\left(r=0.42, F_{1,136}=29.85, P<0.00\right.$; Fig. 5) and fish $\left(r=0.43, F_{1,88}=20.30, P<0.001\right.$; Fig. 5), but not correlated with earthworm $(r=0.14$, $F_{1,32}=18.32, P=0.806$; Fig. 5) and tadpole mass $\left(r=0.2, F_{1,25}=2.36, P=0.136\right.$; Fig. 5).

\section{Variation with snake sex}

Mean body lengths of captured snakes did not differ between sexes of neonates (Student $t_{20}=$ $0.08, P=0.94$ ), juveniles (Student $t_{94}=0.95, P=0.34$ ), or adults (Student $t_{131}=0.13, P=0.90$ ); thus male and female snakes were similar in size.

No differences were found between the diets of male and female snakes. Pooling all sizes of snake, males $(n=124)$ and females $(n=121)$ ate similar proportions of the five main prey taxa $\left(X^{2}=3.82, P=0.43\right)$, both sexes eating mainly fishes, frogs, leeches, and earthworms, and in similar proportions. Males ate two times more tadpoles $(0.13)$ than females $(0.06)$. 
Males and females did not differ in the mass of leeches, earthworms, fishes, frogs and

185

186

187

188

189

190

191

192

193

194

195

196

197

198

199

200

201

202

203

204

205

206

tadpoles that they ate (MANCOVA $F_{1,193}=0.79, P=0.37$ ), and males and females that ate each

prey taxon were similar in length $\left(F_{1,235}=0.91, P=0.34\right)$.

\section{Discussion}

In this study, we provide a broad description of the diet of T. eques on the Mexican Plateau. The results indicate $69 \%$ of total regurgitations contain two major prey: leeches and fish, while the other three main prey are ingested in similar percentages (earthworms, 10.6\%; frogs, 10.2\%; tadpoles, 9.8\%). The diet of T. eques included amphibious prey (frogs), terrestrial prey (earthworms) and aquatic prey (leeches, fish and tadpoles), and occasionally other prey such as axolotls, slugs, lizards, and mice. The main prey include three vertebrates $(65 \%)$ and two invertebrates $(35 \%)$.

The studies that have analyzed the diet of T. eques in Mexico included four local descriptions and in each study T. eques is locally specialized in feeding on only 2-3 prey taxa (Table 1) (Drummond \& Macías Garcia, 1989). This suggests a pattern of spatial variation in the diet of T. eques, presumably by the local availability of prey, for example the temporal variation of prey, which has not yet been explored for T. eques (Gregory \& Nelson, 1991; Tuttle \& Gregory, 2009).

The diet of T. eques can also exhibit ontogenetic variations associated with individual size, changing from terrestrial to aquatic prey as snake size increases (Macías Garcia \& Drummond, 1988; Drummond \& Macías Garcia, 1989). Ontogenetic change by prey taxa in gartersnakes, could be attributed to proximate mechanisms such as morphological constraints that determine the size of ingested prey (Shine, 1991; Arnold, 1993), the availability of potential prey (Krebs, 2009), energy or nutritional needs (Britt, Hicks, \& Bennett, 2006), habituation and 
207 learning (Halloy \& Burghardt, 1990; Ford \& Burghardt, 1993) or genetically programmed 208 preferences (Arnold, 1977; Arnold, 1981; Britt, Hicks, \& Bennett, 2006). In Tecocomulco, Hidalgo, the differential distribution of large and small snakes was interpreted as a possible cause of differences in diet of $T$. eques with differences in the pattern of foraging, so that the snake can be an effective predator in the air-water interface; preying on aquatic prey when they are particularly vulnerable and terrestrial prey being added to the diet only opportunistically (Drummond \& Macías García, 1989).

In our study, the ontogenetic variation in diet of $T$. eques was also found in the relationship between snake size and prey mass. The ingested prey size gradually increases with snake size and large snakes continued eating small prey (Arnold, 1993). This relationship could be interpreted as an ontogenetic telescope (Arnold, 1993), as previously reported for T. eques in a Zacatecas population with Rana berlandieri (Drummond \& Macías García, 1989).

The absence of ontogenetic variation in the regurgitated samples of tadpoles and earthworms in T. eques, is common because in a previous study the annelids were ingested by $T$. eques regardless of snake body size (Macías Garcia \& Drummond (1988). The proximate explanation for this phenomenon is the high availability of these prey during the annual active period of the snake or by a stable ontogenetic preference for invertebrates (Ford \& Burghardt, 1993). The proximate and functional diet determinants of intraspecific variation in T. eques could be explored by local and temporal variation in prey availability and proportions of snake size classes collected. Intraspecific differences in Thamnophis diet have been described for different populations, seasons, years, size classes, and sexes (Rossman, Ford, \& Siegel, 1996). For example, in some species of Thamnophis have been described geographic dietary differences (e.g., T. elegans, T. radix, and T. sirtalis; Kephart, 1982; Kephart \& Arnold, 1982; Tuttle \& 
230 Gregory, 2009) explained by spatial or temporal variation in prey availability (Kephart and 231 Arnold, 1982; Seigel, 1996).

The intersexual variation in food habits has been associated with sexual differences in body size (Shine et al., 1998). Thamnophis eques has been reported as sexually size dimorphic, with males smaller than females in SVL (Manjarrez, 1998); however in this study, the average size of male and female $T$. eques were similar and there were no sexual differences in diet, except that males ate two times more tadpoles than females. This sexual difference in diet can probably be attributed to real diet preference because females and males that ate each prey taxon were similar in length. Generally, large samples revealed no differences between male and female snakes in variety of prey taxa, proportions of different prey taxa and taxon specific prey weight (Shine, 1993), and the males and females that ate each taxon were similar in size. Overall, male and female T. eques differ in size (Manjarrez, Contreras-Garduño, \& Janczur, 2014), microhabitat use (Venegas-Barrera, 2001), seasonal foraging pattern (Drummond \& Macías Garcia, 1989), and diet (Macías Garcia \& Drummond, 1988; Manjarrez, Contreras-Garduño, \& Janczur, 2014). As was found, males and females of this species do not differ in the body size of prey and type of prey consumed. The possible small differences in diet and microhabitat can be expose by larger sample sizes. Prey size and energetic demands may determine developmental transitions to different prey sizes or taxa, whereas sex, in this snake lacking sexual size dimorphism, has little or no influence on diet. However, sexual dimorphism in head dimensions, and eaten prey shape have seldom been searched and it will be essential to measure prey and head traits for $T$. eques to evaluate the function of resource competition between sexes.

\section{Conclusions}


252 In this study, we provide the first broad description of the diet of the snake T. eques on the 253 Mexican Plateau. The two major prey were leeches and fish. The diet of T. eques included 254 amphibious, terrestrial and aquatic prey with ontogenetic variations associated with individual 255 size, changing from terrestrial to aquatic prey as snake size increases. The ontogenetic variation 256 in diet of T. eques was also found in the relationship between snake size and prey mass. The 257 average size of male and female $T$. eques were similar and there were no sexual differences in 258 diet. The proximate and functional diet determinants of intraspecific variation in T. eques could 259 be explored by local and temporal variation in prey availability and proportions of snake size 260 classes collected.

\section{Acknowledgements}

For their assistance in the field and laboratory work we thank Hugh Drummond, Constantino Macías García and all of the students of the Evolutionary Biology Laboratory. We also thank Ruthe J. Smith for her comments and corrections of the typescript. All subjects were treated humanely on the basis of guidelines outlined by the Society for the Study of Amphibians \& Reptiles. C. Zepeda, M. Manjarrez-Zepeda, and J. Manjarrez-Zepeda provided moral support to $\mathrm{JM}$.

\section{References}

Arnold SJ. 1977. Polymorphism and geographic variation in the feeding behavior of the garter snake Thamnophis elegans. Science, 197, 676-678.

Arnold SJ. 1981. Behavioral variation in natural populations. I. Phenotypic, genetic and environmental correlations between chemoreceptive responses to prey in the garter snake, Thamnophis elegans. Evolution, 35, 489-509. 
274 Arnold SJ. 1993. Foraging theory and prey-size-predator-size relations. In: Segiel RA, Collins

275

276

277

278

279

280

281

282

283

284

285

JT, eds. Snakes: Ecology and behavior. New York: McGraw-Hill, 87-115.

[ASIH] American Society of Ichthyologists and Herpetologists. 2004. Guidelines for the Use of Live Amphibians and Reptiles in Field Research. ASIH, Herpetologists League, Society for the Study of Amphibians and Reptiles. (http://iacuc.ucsd.edu/PDF_References/ASIHHL-

SSAR\%20Guidelines\%20for\%20Use\%20of\%20Live\%20Amphibians\%20and\%20Reptil es.htm).

Britt E, Hicks J, Bennett AF. 2006. The energetic consequences of dietary specialization in populations of the garter snake, Thamnophis elegans. The Journal of the Experimental Biology, 209, 3164-3169.

Carpenter CC. 1952. Comparative ecology of the Common Garter Snake (Thamnophis s. sirtalis), the Ribbon Snake (Thamnophis s. sauritus), and the Butler's Garter Snake (Thamnophis butleri). Ecological Monographs, 22, 235-258.

Conant R. 2003. Observations on garter snake of the Thamnophis eques complex in the lakes of the Mexico's transvolcanic belt, with descriptions of new taxa. American Museum of Natural History Central Park West at $79^{\text {th }}$ street, NY.

Conant R, Collins JT. 1998. Reptiles and Amphibians: Eastern-Central North America. Boston, MA: Houghton Mifflin.

Daltry JC, Wuster W, Thorpe RS. 1998. Intraspecific variation in the feeding ecology of the crotaline snake Calloselasma rhodostoma in Southeast Asia. Journal of Herpetology, $32,198-205$. 
296

297

298

299

300

301

302

303

304

305

306

307

308

309

310

311

312

313

314

315

316

317

318

Drummond H, Macías García C. 1989. Limitations of a generalist: a field comparison of foraging snakes. Behaviour, 108, 23-43.

Ford N, Burghardt G. 1993. Perceptual mechanisms and the behavioural ecology of snakes. In: Segiel RA, Collins JT, eds. Snakes: Ecology and behavior. New York: McGraw-Hill, 117-164.

Gotelli NJ. 2001. A Primer of ecology. (3rd ed.) Massachusetts: Sinauer.

Gregory PT, Nelson KJ. 1991. Predation on fish and intersite variation in the diet of common garter snakes, Thamnophis sirtalis, on Vancouver Island. Canadian. Journal of Zoology, 69, 988-994.

Halloy M, Burghardt G. 1990. The comparative imperative: genetics and ontogeny of chemoreceptive prey responses in natrice snakes. Behaviour, 112, 299-317.

Kephart DG. 1982. Microgeographic variation in the diets of garter snakes. Oecologia 52, 287291.

Kephart DG, Arnold SJ. 1982. Garter snake diets in a fluctuating environment: a seven-year study. Ecology 63, 1232-1236.

King BR. 2002. Predicted and observed maximum prey size-snake size allometry. Functional Ecology, 16, 766-772.

Krebs CJ. 2009. Ecology: The experimental analysis of distribution and abundance. (6th ed.) San Francisco: Benjamin Cummings.

Legendre P, Legendre L. 2003. Numerical ecology. (3rd ed.) Amsterdam: Elsevier.

Lozoya H. 1988. Variación geográfica en la dieta de la culebra jarretera del eje neovolcanico (Thamnophis melanogaster). BSc. Thesis, Universidad Nacional Autónoma de México, México. 
Macías Garcia C, Drummond H. 1988. Seasonal and ontogenic variation in the diet of the Mexican garter snake Thamnophis eques, in lake Tecocomulco, Hidalgo. Journal of Herpetology, 22, 129-134.

Manjarrez J. 1998. Ecology of the Mexican Garter Snake (Thamnophis eques) in Toluca, México. Journal of Herpetology, 32, 464-468.

Manjarrez J, Contreras-Garduño J, Janczur MK. 2014. Sexual Size Dimorphism, Diet and Reproduction in the Mexican Garter Snake, Thamnophis eques. Herpetological Conservation and Biology, 9, 163-169.

Mushinsky HR. 1987. Foraging ecology. In: Seigel RA, Collins JT, Novak SS, eds. Snakes: Ecology and evolutionary biology. New York: McGraw-Hill, 302-334.

Rencher AC. 2002. Methods of Multivariate Analysis (2nd ed.). New York: Wiley-Interscience. Rossman DA, Ford NB, Seigel RA. 1996. The Garter Snakes: Evolution and ecology. Norman: OK: University of Oklahoma Press.

Seigel RA. 1996. Ecology and conservation of garter snakes: Masters of plasticity. In: Rossman DA, Ford NB, Seigel RA, eds. The Garter Snakes. Evolution and ecology. Norman, OK: University of Oklahoma Press, 55-89.

Shine R. 1991. Why do larger snakes eat larger prey items?. Functional Ecology 5: 493-502.

Shine R. 1993. Sexual Dimorphism in Snakes. In: Segiel RA, Collins JT, eds. Snakes: Ecology and behavior. New York: McGraw-Hill, 49-86.

Shine R. 1994. Sexual dimorphism in snakes revised. Copeia, 1994, 326-346.

Shine R, Harlow P, Keogh J, Boeadi. 1998. The influence of sex and body size on food habits of a giant tropical snake, Python reticulatus. Functional Ecology, 12, 248-258. 
341 Tuttle KN, Gregory PT. 2009. Food habits of the plains garter snake (Thamnophis radix) at the 342 northern limit of its range. Journal of Herpetology, 43, 65-73.

343 Venegas-Barrera C. 2001. Efecto del ambiente térmico y la disponibilidad de alimento en la 344 disponibilidad de alimento en la distribución y temperatura corporal de la culebra de agua Thamnophis eques. BSc. Thesis, Universidad Autónoma del Estado de México, México.

346 Zar JH. 1984. Biostatistical analysis. (2nd ed.). New Jersey: Prentice Hall International. 
347 Table 1. Percentage of prey reported in the diet of Thamnophis eques in Mexico.

\begin{tabular}{|c|c|c|c|c|c|}
\hline & $\begin{array}{l}\text { Tecocomulco }{ }^{1} \\
126 \text { snakes }\end{array}$ & $\begin{array}{c}\text { Cerrillo }^{2} \\
18 \text { regurgitations }\end{array}$ & $\begin{array}{c}\text { Toluca } \\
\text { Valley } \\
148 \text { snakes }\end{array}$ & Fresnillo $^{4}$ & Present study \\
\hline \multicolumn{6}{|l|}{ Invertebrate } \\
\hline \multicolumn{6}{|l|}{ prey } \\
\hline \multirow[t]{2}{*}{ Earthworm } & 41 & 22 & 20.2 & 2.9 & 10.6 (Eisenia foetida and \\
\hline & & & & & Eisenia sp.) \\
\hline \multirow[t]{3}{*}{ Leech } & 39 & --- & 8.7 & --- & 23.7 (Erpobdella \\
\hline & & & & & punctata and \\
\hline & & & & & Mooreobdella sp.) \\
\hline Slug & 1.0 & 5.5 & --- & --- & 0.4 \\
\hline \multicolumn{6}{|l|}{ Vertebrate } \\
\hline \multicolumn{6}{|l|}{ prey } \\
\hline \multirow[t]{3}{*}{ Fish } & 11 & --- & 29.0 & --- & 42.4 (Girardinichthys \\
\hline & & & & & multiradiatus, Carassius \\
\hline & & & & & auratus) \\
\hline \multirow[t]{2}{*}{ Frog } & 5 & 28 & 10.1 & 69.0 & 10.2 (Rana berlandieri \\
\hline & & & & & and Rana sp.) \\
\hline \multirow[t]{2}{*}{ Tadpole } & 1.5 & 33 & 22.2 & 23.4 & 9.8 (R. berlandieri, Rana \\
\hline & & & & & $s p)$ \\
\hline Other (axolotl, & 4.5 & 11.0 & 9.4 & 4.7 & 3.2 \\
\hline \multicolumn{6}{|l|}{ lizard or } \\
\hline mouse) & & & & & \\
\hline
\end{tabular}

348

349

${ }^{1}$ Macías García \& Drummond, 1988; ${ }^{2}$ Manjarrez, 1998; ${ }^{3}$ Manjarrez, Contreras-Garduño \& Janczur; ${ }^{4}$ Drummond \& Macías García, 1989. 


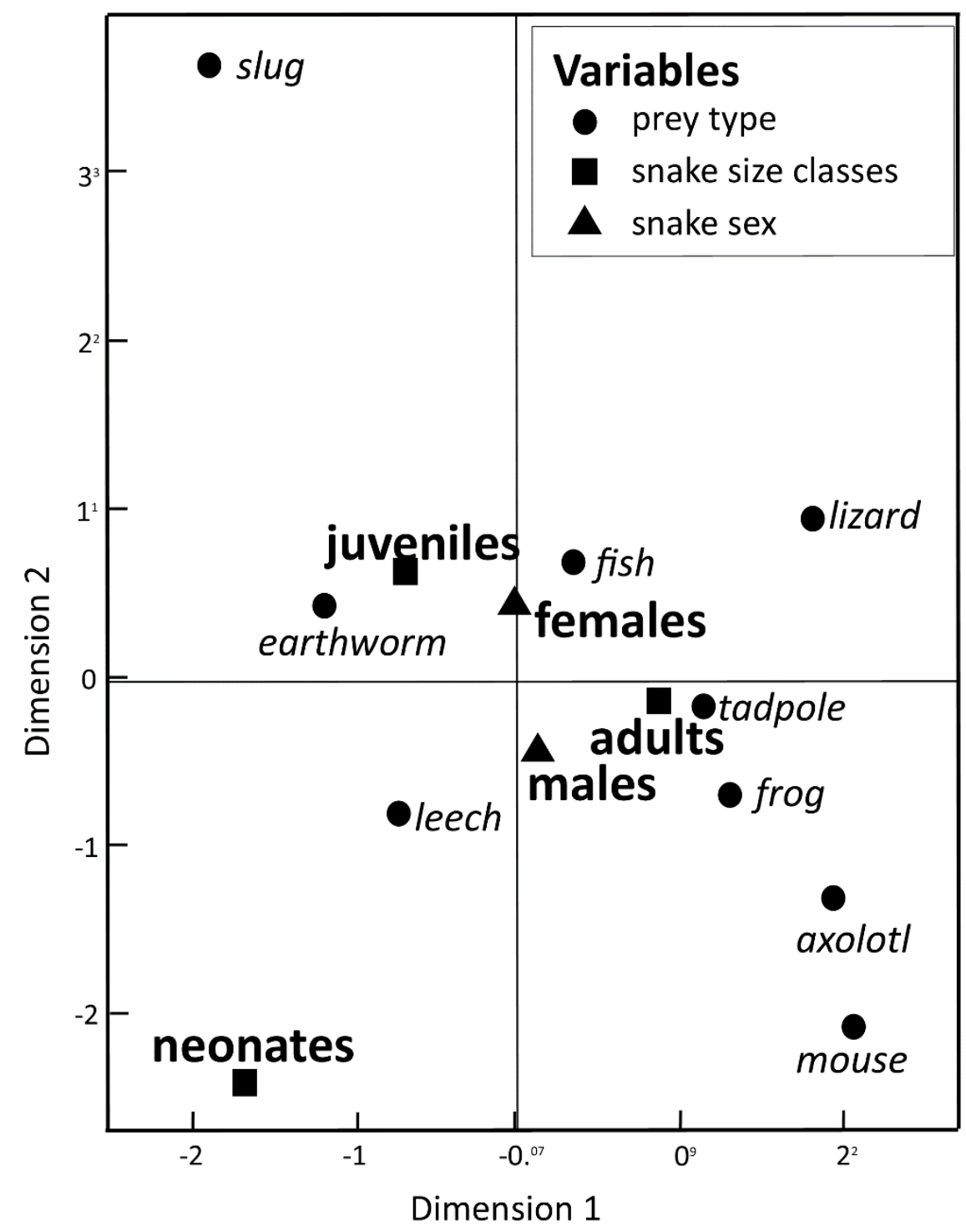

355 Fig. 1. Dimension variables obtained from a Multiple Correspondence Analysis to associate prey 356 items consumed by snake T. eques in the combination of snake sex (male-female) and snake size 357 classes (neonates, juveniles, and adults). 


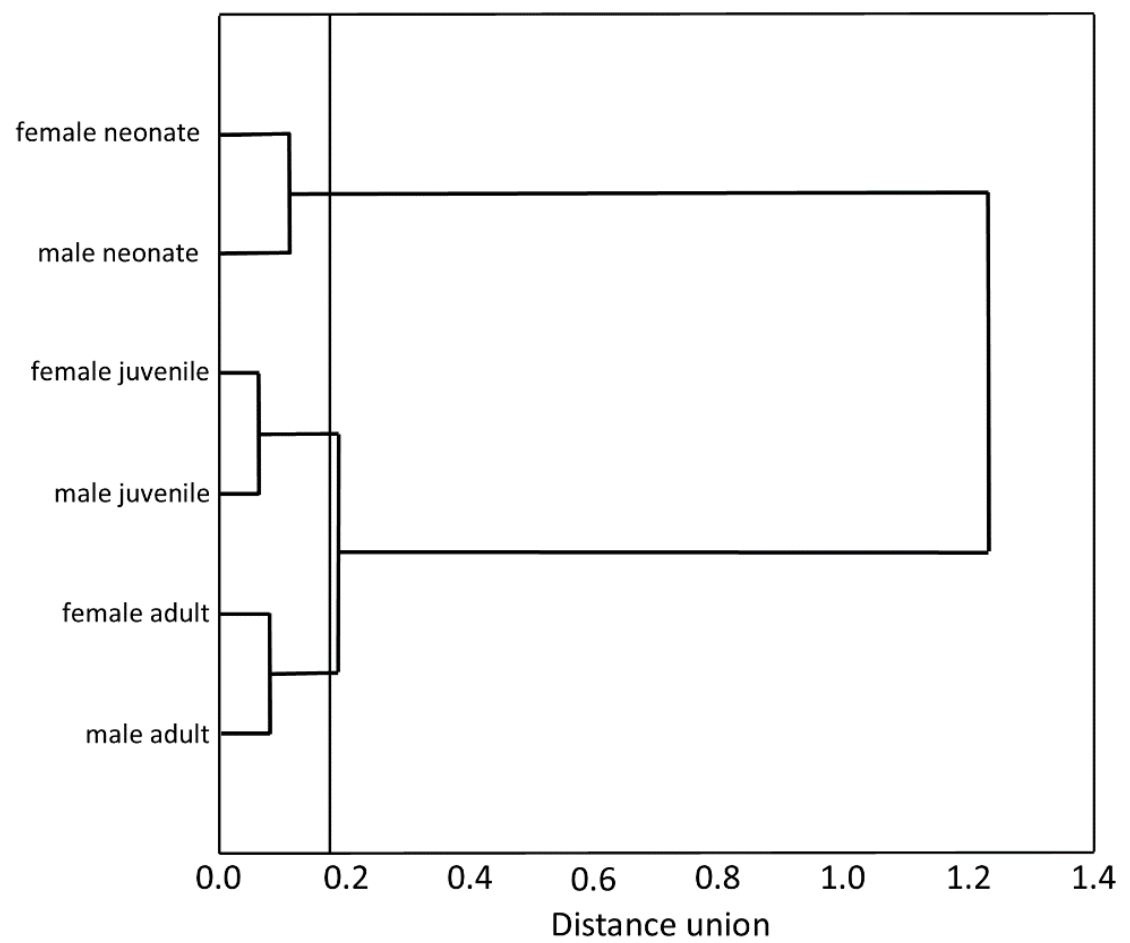

360

Fig. 2. Hierarchical tree produced agglomeration of size classes (neonates, juveniles and adults) and sex (female and male) of T. eques snakes in function of prey type consumed. The amalgamation schedule (Ward's Method) defined in 0.8 the cutoff value for the tree diagram. 
377 Fig. 3. Relationship between prey type and snake size (SVL, cm) of T. eques in México. Each 378 circle represents an individual snake with a type of prey item (262 regurgitations). 


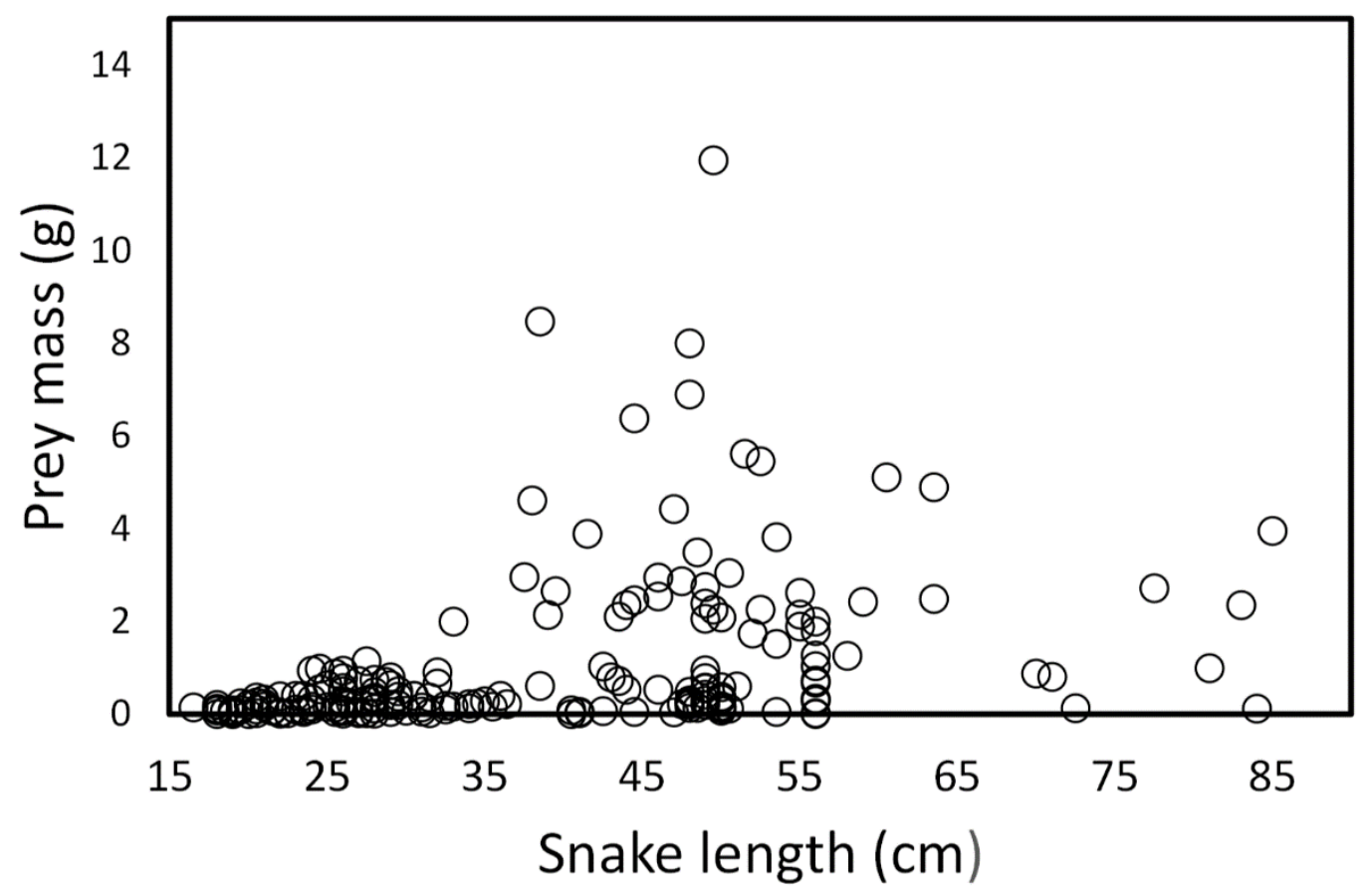

379

Fig. 4. Prey mass as a function of snake length $(\mathrm{SVL}, \mathrm{cm})$ of $(T$. eques $)$ in México. $(r=0.42, F$ $1,326=71.52, P<0.001)$. Each dot represents an individual prey item. The many circles on the zero line of prey mass are because the low weights of leeches and earthworms.

383

384 
403

405

406 Fig. 5. Relation between prey mass and snake length of T. eques. (A) Leeches $(r=0.42, P<$

407 0.00), (B) fish $(r=0.43, P<0.001)$, (C) earthworm $(r=0.14, P=0.806),(\mathrm{D})$ tadpole $(r=0.2, P$

$408=0.136),(\mathrm{E})$ frogs $(r=0.597, \mathrm{P}<0.001)$. 